\title{
Quality of life, psychological adjustment, and adaptive functioning of patients with intoxication-type inborn errors of metabolism - a systematic review
}

\author{
Nina A Zeltner ${ }^{1,2,3,5}$, Martina Huemer ${ }^{1,3}$, Matthias R Baumgartner ${ }^{1,3,4}$ and Markus A Landolt ${ }^{2,5^{*}}$
}

\begin{abstract}
Background: In recent decades, considerable progress in diagnosis and treatment of patients with intoxication-type inborn errors of metabolism (IT-IEM) such as urea cycle disorders (UCD), organic acidurias (OA), maple syrup urine disease (MSUD), or tyrosinemia type 1 (TYR 1) has resulted in a growing group of long-term survivors. However, IT-IEM still require intense patient and caregiver effort in terms of strict dietetic and pharmacological treatment, and the threat of metabolic crises is always present. Furthermore, crises can affect the central nervous system (CNS), leading to cognitive, behavioural and psychiatric sequelae. Consequently, the well-being of the patients warrants consideration from both a medical and a psychosocial viewpoint by assessing health-related quality of life ( $\mathrm{HrQoL}$ ), psychological adjustment, and adaptive functioning. To date, an overview of findings on these topics for IT-IEM is lacking. We therefore aimed to systematically review the research on HrQoL, psychological adjustment, and adaptive functioning in patients with IT-IEM.
\end{abstract}

Methods: Relevant databases were searched with predefined keywords. Study selection was conducted in two steps based on predefined criteria. Two independent reviewers completed the selection and data extraction.

Results: Eleven articles met the inclusion criteria. Studies were of varying methodological quality and used different assessment measures. Findings on HrQoL were inconsistent, with some showing lower and others showing higher or equal HrQoL for IT-IEM patients compared to norms. Findings on psychological adjustment and adaptive functioning were more consistent, showing mostly either no difference or worse adjustment of IT-IEM patients compared to norms. Single medical risk factors for HrQoL, psychological adjustment, or adaptive functioning have been addressed, while psychosocial risk factors have not been addressed.

Conclusion: Data on HrQoL, psychological adjustment, and adaptive functioning for IT-IEM are sparse. Studies are inconsistent in their methodological approaches, assessment instruments and norm populations. A disease-specific standard assessment procedure for HrQoL is not available. Psychosocial risk factors for HrQoL, psychological adjustment, or adaptive functioning have not been investigated. Considering psychosocial variables and their corresponding risk factors for IT-IEM would allow evaluation of outcomes and treatments as well as the planning of effective social and psychological interventions to enhance the patients' HrQoL.

Keywords: Health-related quality of life, Psychological adjustment, Adaptive functioning, Inborn errors of metabolism, Inherited metabolic diseases, Organic acidurias, Urea cycle disorders, Maple syrup urine disease, Tyrosinemia

\footnotetext{
* Correspondence: markus.landolt@kispi.uzh.ch

2Department of Psychosomatics and Psychiatry, Children's Research Center

and University Children's Hospital Zurich, Zurich, Switzerland

${ }^{5}$ Department of Child and Adolescent Health Psychology, Institute of

Psychology, University of Zurich, Zurich, Switzerland

Full list of author information is available at the end of the article
} 


\section{Introduction}

Intoxication-type inborn errors of metabolism (IT-IEM) are a group of inborn errors of metabolism (IEM) which share distinct clinical features. The group encompasses urea cycle disorders (UCD), organic acidurias (OA), tyrosinemia type 1 (TYR 1), and maple syrup urine disease (MSUD). The estimated incidence is between $1: 8,000$ to $1: 44,000$ for UCD [1,2], about 1:21,000 for OA [2], about 1:100,000 for TYR 1 [3] and about 1:185,000 for MSUD [4].

Patients with IT-IEM share two main clinical features: they have to follow a strict diet, and they live with the permanent risk of metabolic crises. These can be triggered by alterations in diet, common infections, or stress but may also occur without predictive circumstances. In cases of metabolic crises, patients immediately require intensified home care or hospitalisation. Despite such efforts, crises remain life-threatening and may cause organ and central nervous system (CNS) damage [5]. To ensure correct diet and an appropriate reaction in risk situations, patients and their families are obliged to develop extensive knowledge about the disease.

Intense biomedical research in the field of IT-IEM has resulted in substantial advances in treatment and a growing group of surviving patients [6]. These individuals have to cope with stressors such as strict diet, medication, crises management, and uncertainties about the future course of their disease and its consequences. Furthermore patients may have behavioural, cognitive, or psychiatric problems due to the CNS alterations caused by the disease [5], which again impair their psychological functioning $[7,8]$. As a result, even though treatments have improved, IT-IEM affect the daily life and well-being of patients and their caregivers considerably [9]. Therefore, complementary research from a psychosocial perspective is especially needed $[9,10]$.

Health-related quality of life (HrQoL), psychological adjustment, and adaptive functioning are well-established constructs to describe psychosocial consequences of chronic diseases. HrQoL has been defined as "a patient's perception of the impact of disease and treatment on functioning in a variety of dimensions, including physical, psychological and social domains" [11], p.126. Adjustment describes the healthy rebalancing of patients to a new condition [12]. We use the more specific term psychological adjustment to refer specifically to emotional, behavioural or social adjustment to a disease. Finally, adaptive functioning is a related term describing "the performance of daily activities required for personal and social sufficiency" ([13], p.6), consisting of the three domains conceptual, practical and social functioning [14]. To date, no consensus has arisen about how HrQoL, psychological adjustment, and adaptive functioning are affected in IT-IEM patients and what factors can influence the well-being of the patients. An overview of findings is lacking. For this reason, we decided to systematically review the current research on HrQoL, psychological adjustment, and adaptive functioning in IT-IEM patients. Our purpose was to answer two research questions:

(1) What is the current state of knowledge about self- and proxy-reported HrQoL, psychological adjustment, and adaptive functioning in IT-IEM patients?

(2)What are the medical and psychosocial risk factors for HrQoL, psychological adjustment, and adaptive functioning in IT-IEM patients?

\section{Methods}

\section{Data sources and search strategies}

To identify eligible studies for our review, we searched relevant databases with pre-defined search terms. The search was conducted using the following electronic bibliographic databases up to 30 April 2013: Pubmed, Embase, Cinahl, PsycINFO, Psyndex and the Cochrane Database of Clinical Trials and Systematic Reviews. NDLTD (Networked Digital Library of Theses and Dissertations) and dissonline.de were searched to find eligible dissertations. We applied two groups of search terms. Firstly, we employed various disease names referring to IEM and IT-IEM. Secondly, we referred to HrQoL, psychological adjustment, and adaptive functioning by employing these terms: quality of life, life satisfaction, well being, well-being, wellbeing, adjustment, adaption, adaptation, adaptive, psycholog*, psychosocial, psychiatr", social, emotional, mental health, mental disorder, mental disease, behavior*, behaviour*. To augment the specificity of the search, the IEM/IT-IEM group and the HrQoL/psychological adjustment/adaptive functioning group were connected to each other by the Boolean operator "AND", whereas terms within the groups were connected by the Boolean operator "OR". We also took advantage of other options to refine the search when the databases offered them; accordingly, search terms concerning IEM, HrQoL, psychological adjustment, and adaptive functioning were limited to titles and abstracts, and words with multiple possible endings or spellings were completed by wildcards. An additional search for studies was conducted in two ways. First, to minimise publication bias, experts in the field were contacted via e-mail and asked if they were aware of any relevant articles or unpublished data. In addition, the references of relevant articles were screened.

\section{Study selection}

To find eligible studies, we rated all the articles and dissertations found in our systematic search according to pre-defined inclusion and exclusion criteria. Studies were included if the number of participants was $\mathrm{N}>1$ and if the sample contained at least 50\% IT-IEM patients 
or if the results of IT-IEM patients were reported separately. Outcomes had to include a self-, proxy-, or examiner's report of patients' HrQoL, patients' psychological adjustment (psychological, social, behavioural, or emotional adjustment), or adaptive functioning. The assessment of these outcomes had to be completed in a standardised way and reported quantitatively. Reporting of methods and results had to be sufficient for replicability. Finally, reports were accepted if they were written in English, German, French, or Spanish. Articles not fulfilling these criteria were excluded. The selection process was conducted in two major steps. First, one reviewer (N.A.Z.) examined all titles and abstracts. Second, studies that could not be excluded in the first examination were rated in their full-text version by two reviewers (N.A.Z. and M.H.) independently. Inter-rater reliability was substantial [10], with Cohen's kappa $=0.79$. Any disagreements were arbitrated through discussion. The remaining articles were included for data extraction.

\section{Data extraction and analysis}

Two reviewers (N.A.Z. and M.A.L.) extracted the data of the articles independently. Inter-rater reliability was almost perfect [15], with Cohen's kappa $=0.98$. Disagreements were resolved through discussion. The great variation between studies regarding design, such as measures and reporting of results, did not permit statistical pooling of data from the individual studies, so meta-analytic calculations were not possible. Instead, effect sizes were calculated whenever possible to attain some comparability between the results. Standardised mean differences, including 95\% confidence intervals (CI), were calculated for continuous outcomes using Cohen's d effect sizes, corrected for small sample sizes [16]. An effect size was considered to be significant if its $95 \%$ CI did not include 0 , thus considering a significance level of $\mathrm{p}<.05$. According to Cohen's categories, an effect size is small if $\mathrm{d}=0.2$ 0.5 , medium if $d=0.5-0.8$ and large if $d>0.8$ [17]. Calculations were conducted such that a positive Cohen's $d$ stands for a higher scoring of the IT-IEM group than of norms. Higher scorings are favourable for all scales, except for two cases: the Child Behaviour Checklist (CBCL) and the Behaviour Assessment System for Children (BASC) (all subscales but adaptive skills) report problem behaviour. Consequently, higher scores signify more problems and are unfavourable outcomes. For dichotomous outcomes, we used Chi-square tests, indicating the strength of the association by Cramer's V, with $\mathrm{p}<.05$ considered significant. IBM SPSS Statistics for Windows, Version 20.0 was used for all calculations.

\section{Results}

The initial search of databases revealed 1669 articles and dissertations. After the first selection, 20 articles remained.
During the second selection process, we had to exclude another nine articles; three were single-case reports, one had the same sample as another article included, and seven articles lacked standardised assessments of the patients' HrQoL, psychological adjustment, or adaptive functioning. One of these articles was a qualitative study [18]. One additional, recently published article [19] was found by contacting experts in the field, and another was traced [20] by screening the references of relevant studies. The search and selection process is depicted in Figure 1. Finally, 11 articles remained for further analyses.

\section{Study description}

The main characteristics and results of the articles included in our review are summarised in Table 1. Further information about the assessment instrument used in the studies can be found in Table 2. Detailed analyses of outcome parameters are shown in Tables 3 and 4 . All 11 articles were published between 2006 and 2013, seven of them in 2012 or 2013. Four articles have their origins in the United States, two in Germany, and one each in Australia, Belgium, Italy, Poland, and Turkey. All articles are written in English. All of the four disease groups we searched for (UCD, OA, MSUD, TYR 1) are represented in the final selection of studies. Patients diagnosed with MSUD ( $\mathrm{n}=124)$ represent the largest group, followed by OA $(\mathrm{n}=107)$, UCD $(\mathrm{n}=100)$ and TYR $1(\mathrm{n}=8)$. Seven studies reported outcomes for only one of these disease groups, four studies included patients of multiple groups. From six articles, only subgroup data were extracted. In four studies, we selected IT-IEM patients from the original samples, which integrated patients with IT-IEM and patients with other diseases [19,21-23]. One study reported on IT-IEM patients before and after transplantation. Only the subgroup before transplantation was selected for further analysis [24]. In another study, outcome regarding adaptive functioning was only available for a subgroup [20]. The final sizes considered ranged from $N=4$ to $N=92$ patients.

Many of the studies had methodological limitations. One main weakness is the lack of appropriate participant selection (i.e. use of convenience samples) in order to avoid selection or non-response bias [22-29]. Two studies involved a non-validated measuring tool $[19,23]$. Furthermore, only two studies considered multiple informants in terms of self- and proxy-ratings [21,28].

\section{Findings on HrQoL Self-report}

As shown in Table 3, results for self-reported HrQoL are inconsistent across studies. In one study, the authors reported significantly lower HrQoL for IT-IEM patients in most domains compared to population norms [28]. The 


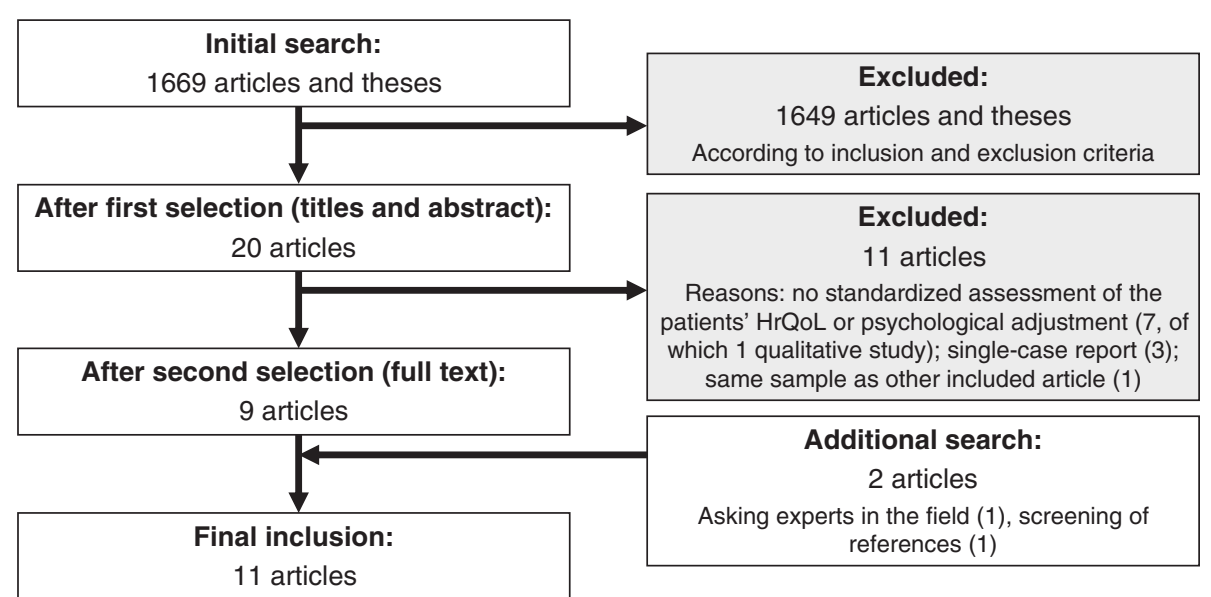

Figure 1 Flowchart of study selection.

results for IT-IEM patients were closer to the results of a cancer population than to a healthy one. Two other studies showed results with more variance throughout the different HrQoL domains. One study reported clearly lower scores for IT-IEM patients than for population norms in the psychological and the friends domains, but higher scores for the school domain [26]. The results for other domains did not differ from norms. Half of the patients in the sample of this study did not categorise themselves as "ill". In contrast, another group of researches reported significantly better scores in the physical domain for IT-IEM patients compared to population norms [22], but lower scores in the environmental domain (including e.g. financial resources, health care, physical environment). The same study found HrQoL of IT-IEM patients to be similar to that of patients with phenylketonuria, who also have to follow a strict diet but who do not face the risk of sudden metabolic crises. Furthermore, IT-IEM patients had higher HrQoL in most domains compared to Morbus Fabry patients, who often have to deal with pain symptoms, and patients with metabolic diseases under pharmacological (as opposed to dietary) treatment [22].

\section{Proxy-report}

Proxy-ratings of HrQoL were all reported by parents. All results for IT-IEM patients were either not different from norms or unfavourable for IT-IEM patients (Table 3). One study showed significantly lower parent-rated HrQoL for IT-IEM patients across all domains compared to population norms [28]. In line with the results for self-reported HrQoL in the same study, the results were closer to cancer population norms than to healthy norms. Psychosocial and social domains were lower in IT-IEM patients than in the cancer population. In another article, the parent-rated HrQoL of IT-IEM patients was compared with the parent-rated HrQoL of patients with other metabolic diseases (aminoacid metabolic disorders and carbohydrate metabolic disorders) [23]. IT-IEM patients scored lower in the domains of school functioning, health perception (compared with both diseases) and physical functioning (only compared with aminoacid metabolic disorders).

\section{Self- vs. proxy-report}

One study [28] compared self- and parent proxy-ratings. The authors reported significantly better scores in selfreported HrQoL for the domains of physical, emotional and social HrQoL, but no difference for school functioning.

\section{Risk factors}

No risk factors regarding HrQoL were investigated in the studies.

\section{Findings on psychological adjustment and adaptive functioning \\ Self-report}

Results for self-reported psychological adjustment and adaptive functioning are shown in Tables 3 and 4. Depression and anxiety (both current and lifetime) were reported to be more prevalent in a group of IT-IEM patients than in a healthy group [24]. However, the study revealed no differences between IT-IEM patients and population norms regarding anxiety and depression symptom severity. Another research group found adaptive functioning for IT-IEM patients to be significantly lower than in a norm population [20].

\section{Proxy-report}

All studies used parent proxy-reports and one additionally used teacher proxy-reports (Tables 3 and 4). Proxy-report findings on different aspects of psychological adjustment and adaptive functioning mostly showed either no difference or worse adjustment and more problems for IT-IEM patients than norms [21,26-29]. Fewer problems 
Table 1 Main characteristics of the reviewed studies

\begin{tabular}{|c|c|c|c|c|c|c|c|}
\hline $\begin{array}{l}\text { Author, } \\
\text { year } \\
\text { (origin) }\end{array}$ & Metabolic disease & $\mathrm{N}^{*}$ & $\begin{array}{l}\text { Reviewed sample vs. } \\
\text { originally reported sample }\end{array}$ & $\begin{array}{l}\text { Mean age in } \\
\text { years (range) }\end{array}$ & $\begin{array}{l}\text { Group of } \\
\text { comparison }\end{array}$ & $\begin{array}{l}\text { Assessment instrument } \\
\text { (report) }\end{array}$ & $\begin{array}{l}\text { Selected results** (IT-IEM } \\
\text { related to group of comparison) }\end{array}$ \\
\hline $\begin{array}{l}\text { Beauchamp } \\
\text { et al., } 2009 \\
\text { (Australia) } \\
{[25]}\end{array}$ & GA I & 4 & Same & 5.8 (5 to 7$)$ & $\begin{array}{l}\text { Population } \\
\text { norms }\end{array}$ & - $\mathrm{CBCL}$ (proxy-mother) & $\begin{array}{l}\text { - Psychological adjustment (CBCL): No } \\
\text { sign. group difference, except for } C B C L \\
\text { total scale, where IT-IEM patients show les } \\
\text { behavioural problems than the norm } \\
\text { population (doubt about reliability of } \\
\text { this result) }\end{array}$ \\
\hline
\end{tabular}

\section{Cazzorla OTCD, HHH Syndrome, et al., 2012 ASA, GA I, MMA, MSUD} (Italy) [22]
15 Reviewed sample: only IT-IEM

Orig. sample: IT-IEM

mixed with other diseases $(\mathrm{N}=82)$
Eminoglu MA, PA, MSUD (group includes et al., $2013 \quad n=3$ patients with a disease (Turkey) [23] not being an (T-IEM) et al., 2013

(Germany)

[19]

ASLD, GA I, IVA, PA, MSUD

34 Reviewed sample: only IT-IEM Orig. sample: IT-IEM mixed

Grünert et al., 2013 (Germany)

[26]
Reviewed sample: separately reported subgroup, mainly IT-IEM, 3 other IEM

Orig. sample: IT-IEM mixed with other IEM $(\mathrm{N}=68)$
4.7 (n.a., $\mathrm{SD}=4.3$ ) Population norms, other IEM-groups: CMD and AMD

- ABAS (proxy-mother)

-WHOQOL-100 (self)

norms, other

IEM-groups: PKU

Morbus Fabry,

pharmacological

treatment

Questionnaire constructed by authors: QoL Scale for Metabolic authors: QoL Scale for

this result)

- Adaptive functioning (ABAS): No sign. group difference

- QoL (WHOQOL-100): Compared to population norms: sign. higher QoL for physical domain, lower for environmental domain, no sign. group difference for all other domains

- QoL (WHOQOL-100): Compared to other IEM: no sign. group difference compared to PKU for all domains, sign higher compared to Morbus Fabry and pharmacologically treated patients in most domains (no sign. group difference for social and environmental domains)

\section{HrQoL (QoL Scale for Metabolic}

Diseases): Sign. lower compared to CMD and AMD for school status and health perception domains, sign. lower in physical function domain compared to AMD, similar for other domains

Kiddy-, Kid- Kiddo-KIND (proxy-parent, self if $>=4$ years) - HrQoL (KINDL): No sign. group difference compared to CMD and AMD for emotional wellbeing domain

4 (1.2 to 9.7) None

Questionnaire constructed

by authors, assessing:
- Perceived burden for the child (proxy-parent)

- Social behavior (proxy-parent)

Psychological adjustment (Perceived burden for the child): Rated as low for the majority $(50 \%)$

\section{- Psychological adjustment (Social} behaviour): Rated average for the majority (82\%)

- Kid-KINDL (self): $\mathrm{n}=18$

- HrQoL (KINDL): Sign. lower HrQoL for psychological and friends domain, sign. higher for school domain, no group difference for other domain 


\begin{tabular}{|c|c|c|c|c|c|}
\hline & & & & $\begin{array}{l}\text { - For Kid-Kindl: } 11 \\
\text { (5 to 18) }\end{array}$ & \\
\hline & & & & $\begin{array}{l}\text { - For SDQ: } 4 \\
\text { (1 to } 18)\end{array}$ & \\
\hline $\begin{array}{l}\text { Krivitzky } \\
\text { et al., } 2009 \\
\text { (USA) [27] }\end{array}$ & UCD & 92 & Same & $7.2(0.4$ to 16.75$)$ & $\begin{array}{l}\text { Population } \\
\text { norms }\end{array}$ \\
\hline $\begin{array}{l}\text { Mazariegos } \\
\text { et al., 2012 } \\
\text { (USA) [20] }\end{array}$ & MSUD & 31 & $\begin{array}{l}\text { Reviewed sample: Patients with } \\
\text { results for adaptive functioning } \\
\text { Orig. sample: Patients with } \\
\text { and without results for } \\
\text { adaptive functioning }(\mathrm{N}=35)\end{array}$ & $\begin{array}{l}9.9(1.7 \text { to } 32.1) \\
\text { (for } N=35)\end{array}$ & $\begin{array}{l}\text { Population } \\
\text { norms }\end{array}$ \\
\hline $\begin{array}{l}\text { Muelly et al., } \\
2013 \text { (USA) } \\
{[24]}\end{array}$ & MSUD & 26 & $\begin{array}{l}\text { Reviewed sample: IT-IEM } \\
\text { patients on diet, not } \\
\text { liver-transplanted } \\
\text { Orig. sample: IT-IEM patients } \\
\text { on diet and IT-IEM after liver } \\
\text { transplantation ( } N=37)\end{array}$ & $\begin{array}{l}\text { - For MSUD diet } \\
n=26: \text { n.a., } \\
\text { Mdn }=19.5 \\
(7 \text { to } 35) \\
\text { - For controls } \\
n=26: \text { n.a., } \\
\text { Mdn = 15.9 } \\
\text { (6 to } 35)\end{array}$ & $\begin{array}{l}\text { Healthy control } \\
\text { group (mostly } \\
\text { siblings of } \\
\text { MSUD-patients) }\end{array}$ \\
\hline
\end{tabular}

-SDQ (proxy-parent): $\mathrm{n}=48$

according to age or degree of mental retardation

- ABAS (proxy-parent): all ages

- CBCL (proxy-parent): for ages $3-16$

- ABAS (self) or Vineland (self) (for this review: only

pre-transplantation assessment)
- Psychological adjustment (SDQ): More problems in all scales except conduct problems

- Adaptive functioning (ABAS): General score was sign. lower for all IT-IEM groups (neonatal onset, late onset, patients with/ without hyperammonemic history) in the age group of 3-16 years

- Adaptive functioning (ABAS): Genera score was sign. lower for the IT-IEM patients with a hyperammonemic history, not for the other subgroups, in the age group of $<3$ years.

- Psychological adjustment (CBCL): No sign. group difference in internalising and externalising problems

\section{- Adaptive functioning (ABAS or}

Vineland): Sign. lower score for adaptive functioning

- Risk factor assessment: Sign positive correlation between IQ and adaptive functioning

- Risk factor assessment: No sign. correlation between adaptive test scores and age at diagnosis, number of preceding metabolic crises, number of preceding metabolic crises, number of
hospitalizations, age at transplantation

- SCID (adult or childhood version) - Psychological adjustment (Severity of for DSM-IV: depression, depression and Anxiety, BDI, BAI, BYI): anxiety, ADHD, global, $\quad$ No sign. group difference psychological functioning (self)

- Psychological adjustment (Current and lifetime depression and anxiety, SCID for DSM-IV): Sign. more lifetime depression and anxiety

BDI and BAI or sub-scores of the BYl of emotional and social impairment (self)
- Risk factor assessment: Patients who remained asymptomatic throughout newborn period vs. patients who were encephalopathic at the time of diagnosis: second group has higher risk to later suffer from anxiety ( $5 x$ higher) and from depression (10x higher)

- Risk factor assessment: Correlation of mood disturbances with some 


\begin{tabular}{|c|c|c|c|c|c|c|}
\hline $\begin{array}{l}\text { Packman } \\
\text { et al., 2007 } \\
\text { (USA) [28] }\end{array}$ & MSUD & 55 & Same & 11 (5 to 18$)$ & $\begin{array}{l}\text { Population } \\
\text { norms }\end{array}$ & $\begin{array}{l}\text { - BASC (proxy-parent, } \\
\text { proxy-teacher) }\end{array}$ \\
\hline $\begin{array}{l}\text { Pohorecka } \\
\text { et al., 2012 } \\
\text { (Poland)[29] }\end{array}$ & TYR I & 8 & Same & 11 (6 to 15$)$ & $\begin{array}{l}\text { Population } \\
\text { norms }\end{array}$ & - CBCL (proxy-parent) \\
\hline \multirow{2}{*}{$\begin{array}{l}\text { Simons } \\
\text { et al., } 2006 \\
\text { (Belgium) } \\
{[21]}\end{array}$} & \multirow[t]{2}{*}{ OTCD, GA III, MMA } & \multirow[t]{2}{*}{11} & \multirow[t]{2}{*}{$\begin{array}{l}\text { Reviewed sample: only IT-IEM } \\
\text { Orig. sample: IT-IEM mixed } \\
\text { with other IEM }(\mathrm{N}=53)\end{array}$} & \multirow[t]{2}{*}{$\begin{array}{l}\text { n.a. }(0-2 \text { to } 16) \\
\text { (for } N=53)\end{array}$} & \multirow[t]{2}{*}{$\begin{array}{l}\text { Population } \\
\text { norms }\end{array}$} & $\begin{array}{l}\text { - CBCL, TRF, YSR (proxy-parent, } \\
\text { proxy-teacher, self if child > } \\
11 \text { years old) }\end{array}$ \\
\hline & & & & & & $\begin{array}{l}\cdot \text { K-SADS for DSM-IV } \\
\text { diagnosis (self) }\end{array}$ \\
\hline
\end{tabular}

biochemical parameters. No strong correlation of depression and anxiety with indices of lifetime metabolic control

HrQoL (PedsQL): Total HrQoL score and domains are closer to cancer sample norms than to healthy sample norms

- Psychological adjustment and daptive functioning (BASC): Mostly no sign. group difference. Sign. more problems in some areas, sign. lower scores in adaptive skills (parent- and teacherrating)

Self- vs. proxy-rating: $\mathrm{HrQoL}$ self-report > proxy-report for physical, emotional, social domain no difference for schoo function

- Self- vs. proxy-rating: Behavioura adjustment proxy parent- vs. proxy eacher-report: paren internalising problems (somatization, anxiety)

- Psychological adjustment (CBCL): Sign. more problems in several scales

- Psychological adjustment (CBCL): № sign. group difference

Psychological adjustment (K-SADS for DSM-IV): Psychiatric diagnoses in $n=2$, but scale was not applied to the whole sample

*The $\mathrm{N}$ reported corresponds to the highest number of participants for which HrQoL/psychological outcome is reported.

**Results are based on the statistic analysis done for this review. A "significant" outcome means that the calculated $95 \% \mathrm{Cl}$ of the effect size does not include the value of zero and is thus significant on a level of $\mathrm{p}<0.05$ (continuous results) or that the $\mathrm{X}^{2}$-test revealed a significant result on a level of $\mathrm{p}<0.05$ or lower (dichotomous results). The statements refer to IT-IEM patients related to the respective group of comparison Abbreviations diseases: AMD (Amino Acid Metabolism Disorders), ASA (Arginosuccinic Aciduria), ASLD (Adenylosuccinate Lyase Deficiency), CMD (Carbohydrate Metabolism Disorders), GA I (Glutaric Aciduria type I), GA III (Glutaric Aciduria type III), HHH Syndrom (Hyperornithinemia-Hyperammonemia-Homocitrullinuria Syndrome), IEM (Inborn Errors of Metabolism), IVA (Isovaleric Aciduria), IT-IEM (Intoxication-type Inbron Errors of Metabolism), MMA (Methylmalonic Aciduria), MSUD (Maple Syrup Urine Disease), OTCD (Ornithintranscarbamylase Deficiency), PA (Propionic Aciduria), TYR I (Tyrosinemia type I), UCD (Urea Cycle Disorder).

Abbreviations assessment instruments: ABAS (Adaptive Behavior Assessment System), BAl (Beck Anxiety Inventory), BASC (Behavior Assessment System for Children), BDI (Beck Depression Inventory), BYI (Beck Youth Inventory), CBCL (Child Behaviour Check List) with YSF (Youth-report form) and TRF (Teacher-report form), DSM-IV (Diagnostic and Statistical Manual of Mental Disorders IV), Kiddy-, Kid-, Kiddo-KINDL (Revised questionnaire to assess health-related quality of life in children and adolescents), K-SADS (Schedule for Affective Disorders and Schizophrenia for School-Age Children), PedsQL (Pediatric Quality of Life Inventory), SDQ (Strengths and Difficulties Questionnaire), SCID (Structured clinical interview for DSM-IV), Vineland (Vineland Adaptive Behavior Scale), WHOQOL-100 (World Health Organisation Quality of Life assessment). 
Table 2 Overview of assessment instruments in the reviewed studies

\begin{tabular}{lll}
\hline Assessment instrument & General use \\
\hline ABAS & $\begin{array}{l}\text { Adaptive behavior } \\
\text { assessment system }\end{array}$ & $\begin{array}{l}\text { Assessment of adaptive behaviour and skills necessary for } \\
\text { daily living, for individuals from birth to } 89 \text { years. Thirte } \\
\text { scales are organised in three general areas: conceptual, } \\
\text { social, practical. Versions for self- and different proxy- } \\
\text { reports are available. }\end{array}$ \\
BAI $\quad$ Beck anxiety inventory & $\begin{array}{l}\text { Assessment of severity of anxiety of individuals aged } \\
\text { from } 17 \text { to } 80 \text { years. Consists of } 21 \text { multiple choice } \\
\text { questions for self-report. }\end{array}$
\end{tabular}

BASC Behavior assessment system for children

BDI

Beck depression inventory

BYI Beck youth inventory

CBCL

Child behaviour check list

KINDL

Revised questionnaire to assess healthrelated quality of life in children and adolescents

K-SADS Schedule for affective disorders and schizophrenia for school-age children

PedsQL Pediatric quality of life inventory interview for DSM-IV
Assessment of behaviour and self-perception of children aged from 2 years 6 months to 18 years. Teacher-, parent- and self-report versions available.

Assessment of severity of depression of individuals aged from 13 to 80 years. Consists of 21 multiple choice questions for self-report.

Consisting of five inventories (anger, anxiety, depression, disruptive behaviour, self-concept) for children and adolescents aged from 7 to 17 years. Each inventory consists of 20 questions for self-report.

Ratings of behavioural, emotional and social functioning of children and adolescents aged from 1 year 6 month to 18 years. Behaviours are categorized into internalising problem scales (e.g. anxiety, somatic complaints) and externalising problem scales (e.g. aggressive behaviour, attention problems). The CBCL is for parent-report, a teacher-report form (TRF) and a youth-report form (YRF) are available.

Generic instrument to assess health-related quality of life in children and adolescents aged from 3 to 17 years.

Version for three age groups are available (Kiddy-, Kid-, Kiddo-KINDL), each in self- and proxy-rating. Dimensions: psychological well-being, social relationships, physical function, everyday life activities.

Semi-structured interview to make DSM-IV (Diagnostic and Statistical Manual of Mental Disorders IV) diagnoses in children and adolescents from aged from 6 to 16 years. Answers from parents and children are both considered.

Assessment of health-related quality of life in children and adolescents aged from 2 to 18 years. Can be used in healthy individuals (generic module) and in those with health conditions (additional diseasespecific modules). Self- and proxy-report versions are available. Consists of 23 items forming the generic module. Disease-specific modules are available e.g. for asthma, diabetes, cancer. Scales: Physical, emotional, social and school functioning.

Semi-structured interview to make DSM-IV (Diagnostic and Statistical Manual of Mental Disorders IV) diagnoses in adults, version for children is available.

Instrument to screen behavioural strengths and difficulties in children and adolescents aged from 3-16 years. Parent- or teacher-report, available in self-report for 11-16 year olds. 25 Items for 5 scales: emotional symptoms, conduct problems, hyperactivity/ inattention, peer relationship problems, prosocial behaviour.

\section{Reference}

Harrison, PL, Oakland, T (2003). Adaptive Behavior

Assessment System - Second Edition. San Antonio, TX: The Psychological Corporation.

Beck, A, Steer, R (1993). Manual for the Beck Anxiety Inventory. San Antonio, Texas, USA: The Psychological Corporation Harchourt Brace \& Company; 1993.

Reynolds CR, Kamphaus RW: Behavior assessment system for children. Circle Pines, MN: American Guidance Service 1992.

Beck AT, Ward CH, Mendelson M, Mock J, Erbaugh J: An inventory for measuring depression. Arch Gen Psychiatry 1961,

4:561-571.

Beck, J, Beck, A, Jolly, J (2001). Beck Youth Inventories of Emotional and Social Impairment. San Antonio, Texas USA: The Psychological Corporation.

Achenbach, TM, \& Rescorla, LA (2000). Manual for the ASEBA Preschool Forms \& Profiles. Burlington, VT: University of Vermont, Research Center for Children, Youth, \& Families.

Ravens-Sieberer U, Bullinger M: Assessing health-related quality of life in chronically ill children with the German KINDL: first psychometric and content analytical results. Qual Life Res 1998, 7:399-407.

Kaufman J, Birmaher B, Brent D, Rao U, Flynn C, Moreci P, Williamson D, Ryan N: Schedule for Affective Disorders and Schizophrenia for School-Age Children-Present and Lifetime Version (K-SADS-PL): initial reliability and validity data. J Am Acad Child Adolesc Psychiatry 1997, 36:980-988.

Varni JW, Seid M, Rode CA: The PedsQL: measurement model for the pediatric quality of life inventory. Med Care 1999, 37:126-139.

First MB, Spitzer, RL, Gibbon, M, Williams, JBW: Structured clinical interview for DSM-IV_TR Axis I Disorders, Research Version, Non-Patient Edition. New York, NY: Biometrics Research, New York State Psychiatric Institute; 2002.

Goodman R: The Strengths and Difficulties Questionnaire: a research note. J Child Psychol Psychiatry 1997, 38:581-586. 
Table 2 Overview of assessment instruments in the reviewed studies (Continued)

\begin{tabular}{|c|c|c|c|}
\hline Vineland & $\begin{array}{l}\text { Vineland adaptive } \\
\text { behavior scale }\end{array}$ & $\begin{array}{l}\text { Assessment of adaptive behaviour and skills necessary for } \\
\text { daily living from birth to } 90 \text { years. Scales refer to } \\
\text { functions necessary for daily living and are organised in } \\
\text { three main areas: Communication, daily living skills, } \\
\text { socialization. Self-, caregiver- and teacher-rating forms are } \\
\text { available. }\end{array}$ & $\begin{array}{l}\text { Sparrow SS, Cicchetti, DV, Balla, DA: Vineland } \\
\text { Adaptive Behavior Scales. Circle Pines, MN: AGS } \\
\text { Publishing; } 2005 .\end{array}$ \\
\hline $\begin{array}{l}\text { WHOQOL- } \\
100\end{array}$ & $\begin{array}{l}\text { World health } \\
\text { organisation quality of } \\
\text { life assessment }\end{array}$ & $\begin{array}{l}\text { Instrument to assess subjective quality of life in adults. } \\
\text { Self- and proxy-report version available. Dimensions: } \\
\text { physical, psychological, independence, social, } \\
\text { environment, religion/spirituality. }\end{array}$ & $\begin{array}{l}\text { The WHOQOL Group: The World Health } \\
\text { Organization Quality of Life Assessment } \\
\text { (WHOQOL): development and general } \\
\text { psychometric properties. Soc Sci Med 1998, } \\
\text { 46:1569-1585. }\end{array}$ \\
\hline
\end{tabular}

compared to population norms were described in one paper [25].

\section{Proxy-parent vs. proxy-teacher-report}

According to one study, teachers reported more internalising problems (somatisation, anxiety) than parents [28].

\section{Risk factors}

For psychological adjustment and adaptive functioning parameters, several risk factors were investigated. The risk for lifetime anxiety or lifetime depression disorders was higher in patients who were encephalopathic at diagnosis than patients who were non-symptomatic at diagnosis [24]. Adaptive functioning correlated with IQ according to another study, but no correlation was found between adaptive functioning and age at diagnosis, number of preceding metabolic crises, or number of hospitalisations [20]. Finally, lower scores in adaptive functioning were found among patients with neonatal onset than among late-onset patients, but no difference was found in the number of hyperammonemic events [27].

\section{Discussion \\ HrQoL, psychological adjustment, and adaptive functioning}

The first aim of our systematic review was to explore the current state of research on HrQoL, psychological adjustment, and adaptive functioning in patients with IT-IEM. We found 11 articles reporting HrQoL, psychological adjustment, or adaptive functioning for this group of patients. Results for HrQoL varied across studies from lower HrQoL to similar and better scores for IT-IEM patients compared to norms. Notably, proxy-ratings of patients' HrQoL were consistently similar or lower than norms. Results for psychological adjustment and adaptive functioning varied less and were mostly comparable to norms or showed worse adjustment for IT-IEM patients. Fewer problems were only reported once [25] - however, this result has to be considered with care. The sample size of this study was very small $(n=4)$ compared to the other studies, and the authors themselves expressed some doubts about the reliability of their results.

Impaired HrQoL, psychological adjustment, or adaptive functioning can have different causes. Firstly, this may be a result of the distress experienced in IT-IEM, such as fear of metabolic crises or social problems associated with the diet [9]. Secondly, neurological sequelae of IT-IEM can lead directly to cognitive or psychological problems and thus to worse psychological adjustment and adaptive functioning in everyday life (e.g. psychotic or depressive symptoms through CNS damage) [5]. Thirdly, it is important to consider the interaction between HrQoL and psychological adjustment, since the literature shows impaired HrQoL in patients with mental disorders [7]. Therefore, impaired HrQoL may be caused by mental health problems. In contrast, good HrQoL in IT-IEM patients may be explained by the theory of response shift [30]. This would account for the often-seen improvement of HrQoL in chronically ill patients as a result of an accommodation process which involves changing internal standards, values and conceptualisation. According to Sprangers and Schwartz [30], a response shift results from the interaction of different variables: health status, mechanisms such as coping, and antecedents such as personality or sociodemographics.

Interestingly, HrQoL was more often reported to be impaired when rated by parents compared to self-ratings by patients. In line with this, a comparison of self- and proxy-ratings revealed better self-ratings in most domains [28]. The fact that HrQoL of children with chronic health conditions is rated lower by parents than by the children themselves is well known from the literature [31]. Furthermore, there is a close relation between the parent's rating of a child's HrQoL and the parent's own HrQoL [32]: Parents experiencing low HrQoL rate their child's HrQoL low as well. This might be especially relevant in parents of children with IT-IEM, since these diseases demand intensive care and may have a great impact on the lives of caregivers [33]. Another explanation for the lower proxyratings may be the ability of parents to anticipate the future problems of the child. Young children in particular may not be aware of these to the same extent. 
Table 3 Continuous outcomes in the reviewed studies

\begin{tabular}{|c|c|c|c|c|c|c|c|}
\hline \multirow{2}{*}{$\begin{array}{l}\text { Reference } \\
\mathrm{N}\end{array}$} & \multirow[b]{2}{*}{ Instrument } & \multirow[b]{2}{*}{ Subscale } & \multirow[b]{2}{*}{ ES ${ }^{1}$ : Cohen's d } & \multicolumn{3}{|c|}{$\mathrm{Cl}$ of $\mathrm{d}$} & \multirow[b]{2}{*}{ Sign } \\
\hline & & & & Lower & & Upper & \\
\hline \multicolumn{8}{|c|}{ Health-related quality of life: self-report } \\
\hline & & & \multicolumn{4}{|c|}{ Compared to population norms } & \\
\hline Cazzorla et al., 2012 [22] & WHOQOL-100 & General & n.a. & n.a. & to & n.a. & n.a. \\
\hline \multirow[t]{25}{*}{$N=15$} & & Physical & 0.62 & 0.10 & to & 1.13 & * \\
\hline & & Psychological & 0.52 & 0.00 & to & 1.04 & ns \\
\hline & & Independence & n.a. & n.a. & to & n.a. & n.a. \\
\hline & & Social & -0.13 & -0.64 & to & 0.39 & ns \\
\hline & & Environmental & -2.43 & -2.97 & to & -1.89 & * \\
\hline & & Spiritual & n.a. & n.a. & to & n.a. & n.a. \\
\hline & & Medication & n.a. & n.a. & to & n.a. & n.a. \\
\hline & & & \multicolumn{4}{|c|}{ Compared to PKU } & \\
\hline & & General & 0.03 & -0.69 & to & 0.74 & ns \\
\hline & & Physical & 0.16 & -0.56 & to & 0.88 & ns \\
\hline & & Psychological & 0.70 & -0.04 & to & 1.44 & ns \\
\hline & & Independence & -0.34 & -1.06 & to & 0.38 & ns \\
\hline & & Social & 0.14 & -0.58 & to & 0.85 & ns \\
\hline & & Environmental & 0.41 & -0.31 & to & 1.14 & ns \\
\hline & & Spiritual & 0.31 & -0.41 & to & 1.04 & ns \\
\hline & & Medication & 0.70 & -0.04 & to & 1.44 & ns \\
\hline & & & \multicolumn{4}{|c|}{ Compared to Morbus Fabry } & \\
\hline & & General & 1.15 & 0.35 & to & 1.95 & * \\
\hline & & Physical & 1.49 & 0.65 & to & 2.33 & * \\
\hline & & Psychological & 0.90 & 0.12 & to & 1.68 & * \\
\hline & & Independence & 1.11 & 0.31 & to & 1.90 & * \\
\hline & & Social & 0.70 & -0.06 & to & 1.47 & ns \\
\hline & & Environmental & 0.91 & 0.13 & to & 1.69 & * \\
\hline & & Spiritual & 1.07 & 0.28 & to & 1.87 & * \\
\hline & & Medication & -0.35 & -1.10 & to & 0.40 & ns \\
\hline
\end{tabular}

Compared to IEM with pharmacological treatment

$\begin{array}{llllll}\text { General } & 0.92 & 0.27 & \text { to } & 1.56 & * \\ \text { Physical } & 1.19 & 0.53 & \text { to } & 1.86 & * \\ \text { Psychological } & 0.94 & 0.30 & \text { to } & 1.59 & * \\ \text { Independence } & 0.74 & 0.11 & \text { to } & 1.38 & * \\ \text { Social } & 0.16 & -0.46 & \text { to } & 0.78 & \text { ns } \\ \text { Environmental } & 0.75 & 0.12 & \text { to } & 1.39 & * \\ \text { Spiritual } & 0.90 & 0.25 & \text { to } & 1.54 & * \\ \text { Medication } & -0.26 & -0.88 & \text { to } & 0.36 & \text { ns }\end{array}$

Grünert et al., 2013 [26] KINDL

$N=18$

$$
N=18
$$

$$
\begin{aligned}
& \text { Cazzorla } \\
& N=15
\end{aligned}
$$

Medication

Total
Physical
Psychological
Self-esteem

\section{Compared to population norms}

$\begin{array}{lllll}-0.34 & -0.81 & \text { to } & 0.12 & \text { ns } \\ -0.28 & -0.74 & \text { to } & 0.19 & \text { ns } \\ -0.78 & -1.25 & \text { to } & -0.32 & * \\ 0.15 & -0.32 & \text { to } & 0.63 & \text { ns }\end{array}$


Table 3 Continuous outcomes in the reviewed studies (Continued)

\begin{tabular}{|c|c|c|c|c|c|c|c|}
\hline & & Family & -0.38 & -0.84 & to & 0.09 & ns \\
\hline & & Friends & -0.68 & -1.14 & to & -0.21 & * \\
\hline & & School & 0.73 & 0.22 & to & 1.24 & * \\
\hline & & Illness & n.a. & n.a. & to & n.a. & n.a. \\
\hline & & & \multicolumn{5}{|c|}{ Compared to healthy population norms } \\
\hline Packman et al., 2007 [28] & PedsQL self-report & Physical function & -0.28 & -0.69 & to & 0.13 & ns \\
\hline \multirow[t]{12}{*}{$N=55$} & & Emotional function & -0.55 & -0.96 & to & -0.14 & * \\
\hline & & Social function & -0.80 & -1.22 & to & -0.39 & * \\
\hline & & School function & -0.70 & -1.12 & to & -0.29 & * \\
\hline & & Psychosocial & -0.85 & -1.27 & to & -0.44 & * \\
\hline & & Total & -0.77 & -1.19 & to & -0.36 & * \\
\hline & & & \multicolumn{5}{|c|}{ Compared to cancer population norms } \\
\hline & & Physical function & 0.42 & 0.00 & to & 0.84 & ns \\
\hline & & Emotional function & -0.04 & -0.46 & to & 0.38 & ns \\
\hline & & Social function & -0.24 & -0.66 & to & 0.19 & ns \\
\hline & & School function & -0.24 & -0.67 & to & 0.18 & ns \\
\hline & & Psychosocial & -0.23 & -0.65 & to & 0.19 & ns \\
\hline & & Total & -0.02 & -0.44 & to & 0.40 & ns \\
\hline \multicolumn{8}{|c|}{ Health-related quality of life: proxy-report } \\
\hline & & & \multicolumn{5}{|c|}{ Compared to CMD } \\
\hline Eminoglu et al., 2013 [23] & QOL scale for metabolic disease & Impact of IEM & -0.18 & -1.02 & to & 0.67 & ns \\
\hline \multirow[t]{21}{*}{$N=14$} & & Attention & -0.42 & -1.15 & to & 0.31 & ns \\
\hline & & Self-esteem about IEM & 0.03 & -0.70 & to & 0.76 & ns \\
\hline & & Physical function & -0.65 & -1.38 & to & 0.08 & ns \\
\hline & & Labeling & -0.57 & -1.41 & to & 0.27 & ns \\
\hline & & Social support & 0.17 & -0.69 & to & 1.03 & ns \\
\hline & & School status & -0.93 & -1.77 & to & -0.09 & * \\
\hline & & Health perception & -1.69 & -2.64 & to & -0.74 & * \\
\hline & KINDL & Emotional wellbeing & -0.44 & -1.07 & to & 0.19 & ns \\
\hline & & & \multicolumn{5}{|c|}{ Compared to AMD } \\
\hline & QOL scale for metabolic disease & Impact of IEM & -0.24 & -1.18 & to & 0.69 & ns \\
\hline & & Attention & -0.64 & -1.43 & to & 0.16 & ns \\
\hline & & Self-esteem about IEM & -0.45 & -1.26 & to & 0.36 & ns \\
\hline & & Physical function & -1.14 & -1.96 & to & -0.33 & * \\
\hline & & Labeling & -0.15 & -1.02 & to & 0.71 & ns \\
\hline & & Social support & -0.55 & -1.47 & to & 0.38 & ns \\
\hline & & School status & -1.41 & -2.41 & to & -0.40 & * \\
\hline & & Health perception & -1.67 & -2.70 & to & -0.64 & * \\
\hline & KINDL & Emotional wellbeing & -0.20 & -0.88 & to & 0.48 & ns \\
\hline & & & \multicolumn{5}{|c|}{ Compared to population norms } \\
\hline & QOL scale for metabolic disease & & n.a. & n.a. & to & n.a. & n.a. \\
\hline & KINDL & & n.a. & n.a. & to & n.a. & n.a. \\
\hline
\end{tabular}


Table 3 Continuous outcomes in the reviewed studies (Continued)

\begin{tabular}{|c|c|c|c|c|c|c|c|}
\hline \multirow[b]{2}{*}{ Packman et al., 2007 [28] } & \multirow[b]{2}{*}{ PedsQL proxy-report } & \multirow[b]{2}{*}{ Physical function } & \multicolumn{5}{|c|}{ Compared to healthy population norms } \\
\hline & & & -1.14 & -1.54 & to & -0.74 & * \\
\hline \multirow[t]{12}{*}{$N=55$} & & Emotional function & -1.19 & -1.59 & to & -0.80 & * \\
\hline & & Social function & -1.48 & -1.88 & to & -1.08 & * \\
\hline & & School function & -1.46 & -1.86 & to & -1.06 & * \\
\hline & & Psychosocial & -1.66 & -2.06 & to & -1.26 & * \\
\hline & & Total & -1.65 & -2.05 & to & -1.25 & * \\
\hline & & & \multicolumn{5}{|c|}{ Compared to cancer population norms } \\
\hline & & Physical function & -0.06 & -0.46 & to & 0.34 & ns \\
\hline & & Emotional function & -0.23 & -0.63 & to & 0.17 & ns \\
\hline & & Social function & -0.65 & -1.05 & to & -0.25 & * \\
\hline & & School function & -0.39 & -0.80 & to & 0.01 & ns \\
\hline & & Psychosocial & -0.54 & -0.94 & to & -0.14 & * \\
\hline & & Total & -0.40 & -0.80 & to & 0.00 & ns \\
\hline
\end{tabular}

Psychological adjustment and adaptive functioning: self-report

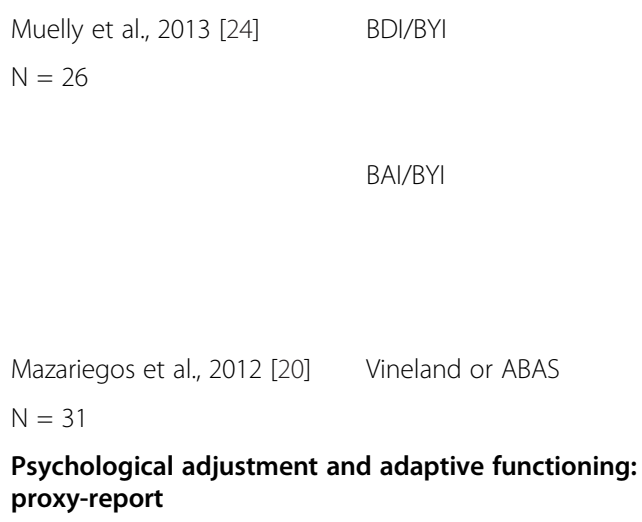

Psychological adjustment and adaptive functioning: proxy-report

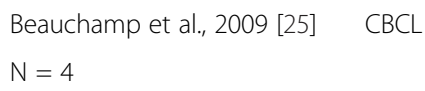

BDI score adults

BYI T-score

Combined z-score

BAI score adults

BYI T-score

Combined z-score

Total

\section{Compared to population norms}

$\begin{array}{lllll}0.54 & -0.02 & \text { to } & 1.11 & \text { ns } \\ -0.44 & -1.01 & \text { to } & 0.12 & \text { ns } \\ 0.19 & -0.36 & \text { to } & 0.75 & \text { ns } \\ 0.38 & -0.18 & \text { to } & 0.94 & \text { ns } \\ -0.28 & -0.83 & \text { to } & 0.28 & \text { ns } \\ 0.13 & -0.43 & \text { to } & 0.68 & \text { ns }\end{array}$

\section{Compared to population norms}

$-1.09$

-1.46 to -0.72

\section{Compared to population norms}

Internalising problems
Externalising problems
Total
General score
Conceptual
Social
Practical

$\begin{array}{lllll}-0.32 & -1.31 & \text { to } & 0.66 & \text { ns } \\ -0.76 & -1.74 & \text { to } & 0.23 & \text { ns } \\ -1.32 & -2.31 & \text { to } & -0.34 & * \\ -0.23 & -1.21 & \text { to } & 0.75 & \text { ns } \\ -0.65 & -1.63 & \text { to } & 0.34 & \text { ns } \\ 0.84 & -0.14 & \text { to } & 1.82 & \text { ns } \\ -0.50 & -1.48 & \text { to } & 0.48 & \text { ns }\end{array}$

Neonatal onset vs. population norms

$\begin{array}{lllll}-0.35 & -0.83 & \text { to } & 0.13 & \text { ns } \\ -2.09 & -2.64 & \text { to } & -1.53 & *\end{array}$

Late onset vs. population norms

$\begin{array}{lllll}-0.67 & -1.42 & \text { to } & 0.07 & \text { ns } \\ -0.76 & -1.04 & \text { to } & -0.47 & *\end{array}$


Table 3 Continuous outcomes in the reviewed studies (Continued)

\begin{tabular}{|c|c|c|c|c|c|c|c|}
\hline & & & $\begin{array}{l}\text { Hyp.an } \\
\text { norms }\end{array}$ & $>0$ vs. & pula & & \\
\hline & ABAS, age $<3$ y & General score & -0.37 & -0.88 & to & -0.37 & * \\
\hline & ABAS, age $3-16 y$ & General score & -1.00 & -1.33 & to & -0.99 & * \\
\hline & & & $\begin{array}{l}\text { Hyp.an } \\
\text { norms }\end{array}$ & $=0$ vs. & pula & & \\
\hline & ABAS, age $<3$ y & General score & -0.55 & -1.20 & to & 0.11 & ns \\
\hline & ABAS, age $3-16 y$ & General score & -0.96 & -1.36 & to & -0.56 & * \\
\hline & & & Compa & sulation & orms & & \\
\hline Packman et al., 2007 [28] & BASC parent-report & Hyperactivity & 0.26 & -0.03 & to & 0.55 & ns \\
\hline$N=55$ & & Aggression & 0.24 & -0.04 & to & 0.53 & ns \\
\hline & & Conduct problems & 0.03 & -0.25 & to & 0.32 & ns \\
\hline & & Anxiety & 0.05 & -0.24 & to & 0.34 & ns \\
\hline & & Depression & 0.08 & -0.21 & to & 0.36 & ns \\
\hline & & Somatization & 0.21 & -0.08 & to & 0.50 & ns \\
\hline & & Atypicality & 0.30 & 0.01 & to & 0.59 & * \\
\hline & & Withdrawal & 0.04 & -0.24 & to & 0.33 & ns \\
\hline & & Attention problems & 0.68 & 0.39 & to & 0.97 & $*$ \\
\hline & & Externalising problems & 0.21 & -0.08 & to & 0.50 & ns \\
\hline & & Internalising problems & 0.14 & -0.15 & to & 0.43 & ns \\
\hline & & Behavioral sympt. index & 0.37 & 0.08 & to & 0.66 & * \\
\hline & & Adaptive skills & -0.59 & -0.88 & to & -0.30 & * \\
\hline & & & Compa & pulation & orms & & \\
\hline & BASC teacher-report & Hyperactivity & 0.41 & 0.07 & to & 0.76 & * \\
\hline & & Aggression & 0.28 & -0.07 & to & 0.62 & ns \\
\hline & & Conduct problems & -0.18 & -0.52 & to & 0.16 & ns \\
\hline & & Anxiety & 0.55 & 0.20 & to & 0.89 & * \\
\hline & & Depression & 0.11 & -0.23 & to & 0.45 & ns \\
\hline & & Somatization & 0.66 & 0.32 & to & 1.01 & * \\
\hline & & Attention problems & 0.75 & 0.41 & to & 1.10 & * \\
\hline & & Learning problems & 0.74 & 0.39 & to & 1.08 & * \\
\hline & & Atypicality & 0.68 & 0.34 & to & 1.03 & * \\
\hline & & Withdrawal & 0.19 & -0.15 & to & 0.53 & ns \\
\hline & & Externalising problems & 0.23 & -0.12 & to & 0.57 & ns \\
\hline & & Internalising problems & 0.56 & 0.21 & to & 0.90 & * \\
\hline & & School problems & 0.76 & 0.42 & to & 1.11 & * \\
\hline & & Behavioral sympt. index & 0.62 & 0.28 & to & 0.97 & * \\
\hline & & Adaptive Skills & -0.36 & -0.71 & to & -0.02 & * \\
\hline & & & Compa & sulation & orms & & \\
\hline Pohorecka et al., 2012 [29] & $\mathrm{CBCL}$ & Internalising problems & 1.14 & 0.44 & to & 1.84 & * \\
\hline$N=8$ & & Externalising problems & 0.77 & 0.08 & to & 1.47 & * \\
\hline & & Withdrawn & 1.30 & 0.60 & to & 2.01 & * \\
\hline & & Somatic complaints & 1.19 & 0.49 & to & 1.90 & * \\
\hline & & Anxious depressed & 0.62 & -0.08 & to & 1.32 & ns \\
\hline & & Social problems & 1.52 & 0.82 & to & 2.23 & $*$ \\
\hline & & Thought problems & 0.89 & 0.19 & to & 1.59 & * \\
\hline
\end{tabular}


Table 3 Continuous outcomes in the reviewed studies (Continued)

\begin{tabular}{|c|c|c|c|c|c|c|c|}
\hline & & Attention problems & 1.15 & 0.45 & to & 1.86 & * \\
\hline & & Rule breaking behaviour & 1.07 & 0.37 & to & 1.77 & * \\
\hline & & Aggressive behaviour & 0.86 & 0.16 & to & 1.56 & * \\
\hline & & & \multicolumn{5}{|c|}{ Compared to population norms } \\
\hline Simons et al., 2006 [21] & $\mathrm{CBCL}$ & Internalising problems & 0.79 & -0.02 & to & 1.59 & ns \\
\hline \multirow[t]{2}{*}{$N=11$} & & Externalising problems & 0.36 & -0.44 & to & 1.17 & ns \\
\hline & & Total & 0.64 & -0.17 & to & 1.44 & ns \\
\hline
\end{tabular}

${ }^{1} \mathrm{~A}$ positive value means that the IT-IEM group scored higher than the control group. A negative value means that the IT-IEM group scored lower than the control group. Higher values are favourable in all scales except for the BASC [28] where high scores mean more problems (exception: BASC subscale adaptive skills). Abbreviations: ABAS (Adaptive Behavior Assessment System), BAI (Beck Anxiety Inventory), BASC (Behavior Assessment System for Children), BDI (Beck Depression Inventory), BYI (Beck Youth Inventory), CBCL (Child Behaviour Check List), KINDL (Revised questionnaire to assess health-related quality of life in children and adolescents), PedsQL (Pediatric Quality of Life Inventory), Vineland (Vineland Adaptive Behavior Scale), WHOQOL-100 (World Health Organization Quality of Life assessment).

A major reason for the inconsistent findings may be attributed to methodological issues. Most of the HrQoL instruments were not specifically tailored to patients with IT-IEM. One study used an invalidated diseasespecific instrument [23]. In addition, the HrQoL of IT-IEM patients was compared to different groups: population norms or other metabolic diseases. Sample sizes were often small, a state of affairs that is often found in paediatric research and especially in research in the field of rare diseases. Statistically, such small sample sizes make it more difficult to detect group differences. In addition, one study had a clear selection bias by only including patients who were cognitively able to answer questionnaires [26]. Another significant limitation is the choice of informants; most studies used proxy-reports which do not fully reflect self-reports of the patients. It is clear from the literature that these two kinds of reports are not interchangeable [32].

\section{Risk factors for HrQoL, psychological adjustment, and adaptive functioning}

The second aim of this review was to detect risk factors for HrQoL, psychological adjustment, and adaptive functioning for IT-IEM patients. Only a few risk factors for psychological adjustment and adaptive functioning have been investigated so far, and none have been examined for HrQoL. The risk factors examined were mainly medical $[20,24,27]$. With regard to cognitive parameters, IQ was investigated in one study [20]. Two studies revealed that metabolic events in the neonatal period were associated with psychosocial adjustment: patients diagnosed as encephalopathic newborns had a higher risk of suffering from anxiety or depression during their lifetime than patients who were metabolically stable during the newborn period [24]. Adaptive functioning scores were lower for neonatal-onset than for late-onset patients [27]. Similar results have been found before and may be explained by the fact that crises have a negative impact on the developing brain, especially in highly vulnerable newborns [24,34].

\section{Strengths and limitations of this review}

This systematic review was conducted in accordance to the PRISMA guidelines (Preferred Reporting Items for Systematic Reviews and Meta-Analysis) [35]. In order to find as many eligible studies as possible, we applied several search strategies: we searched different databases and did not restrict the search to English articles. Additionally, we tried to find additional and/or unpublished studies by reference screening and contacting experts in the field. Study selection and data extraction were conducted independently by two reviewers, thereby diminishing the risk of bias. The main weakness of our review is the inability to pool results from the different studies. The different study designs and assessment methods did not permit such meta-analytic calculations. Nevertheless, better comparability of the results was attained by indicating effect sizes and their CI. Another limitation of this systematic review can be found in our comparison of studies with very different sample sizes (ranging from $\mathrm{N}=4$ to $\mathrm{N}=92$ ), the reason why the calculated effect sizes have to be interpreted carefully. Because the incidence rates of rare diseases are small and because there is only a very limited number of studies that could be included in our review, we decided not to exclude studies with small sample sizes (inclusion criterion $\mathrm{N}>1$ ). To account for this limitation, we considered sample sizes in the calculation of effect sizes by correcting mechanisms. The different sizes were also taken into account by computing CIs of effect sizes.

\section{Suggestions for future research}

Based on the findings of this review, several implications can be drawn. Firstly, HrQoL should be considered as an essential outcome parameter in future clinical trials. Up to now, treatment evaluations of patients with IT-IEM have predominantly focused on medical outcomes. However, because survival rates have increased considerably, improvement of HrQoL for patients with IT-IEM must be an additional major goal of new treatments. 
Table 4 Dichotomous outcomes in the reviewed studies

\begin{tabular}{|c|c|c|c|c|c|}
\hline $\begin{array}{l}\text { Reference } \\
\mathrm{N}\end{array}$ & Instrument & Subscale & n IT-IEM & $\begin{array}{l}n \\
\text { control }\end{array}$ & Results \\
\hline \multicolumn{6}{|c|}{ Psychological adjustment, self-report } \\
\hline $\begin{array}{l}\text { Muelly et al., } 2013 \\
\text { [24] }\end{array}$ & SCID, DSM-IV & Depression current & 26 & 26 & $29 / 4$ \\
\hline \multirow[t]{3}{*}{$N=26$} & & Depression lifetime & 26 & 26 & $42 / 19$ \\
\hline & & Anxiety current & 26 & 26 & $42 / 15$ \\
\hline & & Anxiety lifetime & 26 & 26 & $58 / 31$ \\
\hline
\end{tabular}

Test of between group

Cramer's V

significance

Psychological adjustment, proxy-report

Gramer et al., 2013
[19]
$N=34$

Perceived burden for the 34 child

\section{n IT-IEM in different categories ( $\mathbf{n}$ control n.a.)}

Compared to healthy control
group

$\chi^{2}=22.68 ; d f=1$

$p\left(2\right.$-tail) $=0.000^{(* * *)}$

$\chi^{2}=12.48 ; d f=1$;

$p\left(2\right.$-tail) $=0.000{ }^{* * *}$

$\chi^{2}=17.89 ; d f=1 ;$

$p\left(2\right.$-tail) $=0.000^{(* * *)}$

$\chi^{2}=14.96 ; d f=1 ;$

$p\left(2\right.$-tail) $=0.000^{(* * *)}$

heavy $(\mathrm{n}=3)$

\begin{tabular}{|c|c|c|c|}
\hline \multirow[t]{3}{*}{ Social behaviour } & 34 & none & $\begin{array}{l}\text { Lower than norm }(n= \\
\text { norm }(n=3)\end{array}$ \\
\hline & & & $\%$ normal/at risk/clin \\
\hline & & & (\% normal/at risk/clir \\
\hline Emotional symptoms & 48 & 930 & $62 / 13 / 25(84 / 7 / 9)$ \\
\hline Conduct problems & 46 & 930 & $54 / 26 / 20(69 / 16 / 15)$ \\
\hline Hyperactivity/Inattention & 47 & 930 & $62 / 28 / 10(86 / 6 / 8)$ \\
\hline Peer relationship problem & 46 & 930 & $39 / 20 / 41(78 / 11 / 12)$ \\
\hline Prosocial behaviour & 47 & 930 & $57 / 9 / 34(89 / 7 / 4)$ \\
\hline Influence on child's life & 48 & 930 & 60/11/29 (n.a.) \\
\hline Total & 46 & 930 & $52 / 20 / 28(85 / 8 / 7)$ \\
\hline
\end{tabular}

n.a.

Compared to population norms

Grünert et al., 2013 SDQ [26]

$N=48$

SDQ

Total

46

$$
\begin{aligned}
& \chi^{2}=12.64 ; d f=2 ; \\
& p\left(2 \text {-tail) }=0.0022^{(* *)}\right. \\
& \chi^{2}=4.93 ; d f=2 ; \\
& p(2 \text {-tail) }=0.085 \text { (ns) } \\
& \chi^{2}=18.35 ; d f=2 ; \\
& p\left(2 \text {-tail) }=0.0000^{(* *)}\right. \\
& \chi^{2}=32.92 ; d f=2 ; \\
& p\left(2 \text {-tail) }=0.0000^{(* *)}\right. \\
& \chi^{2}=30.95 ; d f=2 ; \\
& p\left(2 \text {-tail) }=0.000^{(* * *)}\right. \\
& \text { n.a. } \\
& \chi^{2}=25.69 ; d f=2 ; \\
& p(2 \text { tail })=0.000^{(* *)}
\end{aligned}
$$


Table 4 Dichotomous outcomes in the reviewed studies (Continued)

\begin{tabular}{|c|c|c|c|c|c|c|c|}
\hline & & & & & $\begin{array}{l}\text { \% normal/at risk/clinically sign. IT-IEM } \\
\text { (\% normal/at risk/clinically sign. control) }\end{array}$ & $\begin{array}{l}\text { Compared to population } \\
\text { norms }\end{array}$ & \\
\hline $\begin{array}{l}\text { Krivitzky et al., } 2009 \\
\text { [27] }\end{array}$ & $\mathrm{CBCL}$ & Internalising problems & 68 & 576 & 79/17/4 (83/7/11) & $\begin{array}{l}\chi^{2}=5.87 ; d f=2 ; \\
p(2 \text {-tail) }=0.053 \text { (ns) }\end{array}$ & 0.17 \\
\hline$N=92$ & & Externalising problems & 68 & 576 & $80 / 16 / 4(83 / 7 / 11)$ & $\begin{array}{l}\chi^{2}=5.26 ; d f=2 ; \\
p(2 \text {-tail) }=0.072 \text { (ns) }\end{array}$ & 0.16 \\
\hline
\end{tabular}

Abbreviations: CBCL (Child Behaviour Check List), DSM-IV (Diagnostic and Statistical Manual of Mental Disorders IV), SCID (Structured Clinical Interview for DSM-IV), SDQ (Strengths and Difficulties Questionnaire). 
Secondly, it is important to increase the methodological quality of psychosocial research among IT-IEM patients. Multicentre studies are necessary both to avoid convenience sampling with a high risk for biased data and to increase sample sizes. International patient registries (e.g. E-IMD, www.e-imd.com) can help to achieve this goal and to aggregate knowledge. This review has shown that a variety of assessment instruments is currently in use, thus complicating the pooling of results. Most of the studies used generic, non-disease-specific instruments. Only one of the reviewed studies used a disease-specific scale [23]; however, this was not validated. Generic instruments have the advantage that results can usually be compared to a healthy population or a population with another disease [6]. However, they do not assess the specific problems of medical conditions. In contrast, disease-specific HrQoL scales are related to the distinct effects of a particular disease [5]. They are more sensitive for special topics that are of interest and more meaningful for specific groups of patients. The use of disease-specific HrQoL assessment measures in clinical trials has been shown to be valuable in other severe medical conditions [5]. To date, no validated, disease-specific measure is available for patients with IT-IEM. Furthermore, from a methodological viewpoint, it is desirable to consider different informants; because proxy-reports have several limitations, the patients' well-being should also be assessed using self-ratings.

Thirdly, knowledge of risk factors influencing HrQoL, psychological adjustment, and adaptive functioning is of great importance. Very few studies have addressed this topic at all, and where they did, research was restricted to medical or biochemical parameters or IQ. Medical parameters are weak predictors for HrQoL in most chronic diseases [5]. In contrast, a systematic review exploring HrQoL in rare genetic conditions has emphasised that parameters explaining how patients coped with their disease were good predictors of HrQoL [5]. As an example, the authors mentioned scales such as "acceptance of disability" or "sense of coherence", which were positive predictors for QoL, while feeling hopeless or having a fatalistic view correlated with lower QoL [5]. Other predictors for HrQoL in chronic disease described in the literature include concepts such as locus of control, attachment, or well-being of the parents [8,36,37]. In IT-IEM patients, such individual and familial psychosocial risk factors have not yet been studied. Current research is, unfortunately, still focused on a fully biomedical model, instead of including the promising psychosocial perspective [5].

\section{Clinical implications}

The small number of studies, partially inconsistent results, and the few risk factors addressed make it difficult to draw implications for clinical practice. Since HrQoL, psychological adjustment, and adaptive functioning seem to be impaired in some patients, we suggest offering psychological support for patients and their families to help them cope more effectively with the disease. Knowing more about risk factors would allow the development of targeted interventions for certain groups of patients. Overall, we consider it important to support patients and their families with a comprehensive care model, including psychological and social interventions to complement the medical ones $[12,21]$.

\section{Conclusion}

Research data on psychosocial factors in IT-IEM patients are generally sparse. However, the growing interest in the topic is underlined by the fact that seven of the 11 articles reviewed were published in 2012 or 2013. Further research and improved methodological quality of studies are required. Multicentre studies and the use of a standardised, disease-specific assessment tools are needed to establish HrQoL as an important additional outcome parameter in patient-centred research and clinical trials.

\section{Abbreviations}

BASC: Behavior Assessment System for Children; CBCL: Child Behaviour Checklist; CNS: Central nervous system; HrQoL: Health-related quality of life; IEM: Inborn errors of metabolism; IT-IEM: Intoxication-type inborn errors of metabolism; MSUD: Maple syrup urine disease; OA: Organic acidurias; TYR 1: Tyrosinemia type 1; UCD: Urea cycle disorders.

\section{Competing interests}

The authors declare that they have no competing interests.

\section{Authors' contributions}

NAZ carried out the search and selection of the articles, extracted the data and drafted the manuscript. MH participated in the selection process of the articles, was involved in the design of the study, and critically reviewed the manuscript. MRB conceived of the study, was involved in the design of the study, and critically reviewed the manuscript. MAL participated in the data extraction process, helped in drafting and revising the manuscript and coordinating the study. All authors read and approved the final version of the manuscript.

\section{Acknowledgements}

This systematic review was supported by radiz - Rare Disease Initiative Zurich, Clinical Research Priority Program for Rare Diseases, University of Zurich, Switzerland. We want to thank the following researchers who provided us with additional information about their published data (in alphabetical order): Marta Biernacka, Chiara Cazzorla, Gwendolyn Gramer, Sarah Grünert, Lauren Krivitzky, Wendy Packman, Annik Simons, and Diana Shellmer.

\section{Author details}

1Division of Metabolism, Children's Research Center and University Children's Hospital Zurich, Zurich, Switzerland. 'Department of Psychosomatics and Psychiatry, Children's Research Center and University Children's Hospital Zurich, Zurich, Switzerland. ${ }^{3}$ Radiz - Rare Disease Initiative Zurich, Clinical Research Priority Program for Rare Diseases, University of Zurich, Zurich, Switzerland. ${ }^{4}$ Zurich Center for Integrative Human Physiology, University of Zurich, Zurich, Switzerland. ${ }^{5}$ Department of Child and Adolescent Health Psychology, Institute of Psychology, University of Zurich, Zurich, Switzerland.

Received: 23 May 2014 Accepted: 6 October 2014

Published online: 25 October 2014 


\section{References}

1. Brusilow S, Maestri NE: Urea cycle disorders: diagnosis, pathophysiology, and therapy. Adv Pediatr 1996, 43:127-170.

2. Dionisi-Vici C, Rizzo C, Burlina AB, Caruso U, Sabetta G, Uziel G, Abeni D: Inborn errors of metabolism in the Italian pediatric population: a national retrospective survey. J Pediatr 2002, 140:321-327.

3. De Laet C, Dionisi-Vici C, Leonard JV, McKiernan P, Mitchell G, Monti L, De Baulny HO, Pintos-Morell G, Spiekerkotter U: Recommendations for the management of tyrosinaemia type 1. Orphanet J Rare Dis 2013, 8:8.

4. Chuang DT, Shih VE: Maple syrup urine disease (branched-chain ketoaciduria). In The Metabolic and Molecular Bases of Inherited Disease. Volume II. 8th edition. Edited by Scriver CR, Beaudet AL, Sly WS, Valle D. New York: McGraw-Hill; 2001:1971-2005.

5. Walterfang M, Bonnot O, Mocellin R, Velakoulis D: The neuropsychiatry of inborn errors of metabolism. J Inherit Metab Dis 2013, 36:687-702.

6. Cohen JS, Biesecker BB: Quality of life in rare genetic conditions: a systematic review of the literature. Am J Med Genet A 2010, 152A:1136-1156.

7. Dey M, Landolt MA, M-K M: Health-related quality of life among children with mental disorders: a systematic review. Qual Life Res 2012, 21:1797-1814.

8. Fan SY, Eiser C, Ho MC: Health-related quality of life in patients with hepatocellular carcinoma: a systematic review. Clin Gastroenterol Hepatol 2010, 8:559-564. e551-510.

9. Weber SL, Segal S, Packman W: Inborn errors of metabolism: psychosocial challenges and proposed family systems model of intervention. Mol Genet Metab 2012, 105:537-541.

10. Gentile JK, Ten Hoedt AE, Bosch AM: Psychosocial aspects of PKU: hidden disabilities - a review. Mol Genet Metab 2010, 99(Suppl 1):S64-67.

11. Varni JW, Seid M, Rode CA: The PedsQL: measurement model for the pediatric quality of life inventory. Med Care 1999, 37:126-139.

12. De Ridder D, Geenen R, Kuijer R, Van Middendorp H: Psychological adjustment to chronic disease. Lancet 2008, 372:246-255.

13. Sparrow SS, Cicchetti DV, Balla DA: Vineland Adaptive Behavior Scales, 2nd edition (Vineland-II): Survey forms manual. Minneapolis, MN: Pearson; 2005

14. American Association on Mental Retardation (AAMR): Mental Retardation Definition, Classification, and Systems of Supports. 10th edition. Washington, DC: American Association on Mental Retardation; 2002.

15. Landis JR, Koch GG: The measurement of observer agreement for categorical data. Biometrics 1977, 33:159-174.

16. Durlak JA: How to select, calculate, and interpret effect sizes. $J$ Pediatr Psychol 2009, 34:917-928.

17. Cohen J: Statistical power analysis for the behavioural sciences. 2nd edition. Hillsdale, NJ: Lawrence Erlbaum Associates; 1988.

18. Packman W, Mehta I, Rafie S, Mehta J, Naldi M, Mooney KH: Young adults with MSUD and their transition to adulthood: psychosocial issues. J Genet Couns 2012, 21:692-703.

19. Gramer G, Haege G, Glahn EM, Hoffmann GF, Lindner M, Burgard P: Living with an inborn error of metabolism detected by newborn screening parents' perspectives on child development and impact on family life. J Inherit Metab Dis 2013, 37:189-195.

20. Mazariegos GV, Morton DH, Sindhi R, Soltys K, Nayyar N, Bond G, Shellmer D, Shneider B, Vockley J, Strauss KA: Liver transplantation for classical maple syrup urine disease: long-term follow-up in 37 patients and comparative United Network for Organ Sharing experience. J Pediatr 2012, 160:116-121 e111.

21. Simons A, Eyskens F, De Groof A, Van Diest E, Deboutte D, Vermeiren R: Cognitive functioning and psychiatric disorders in children with a metabolic disease. Eur Child Adolesc Psychiatry 2006, 15:207-213.

22. Cazzorla C, Del Rizzo M, Burgard P, Zanco C, Bordugo A, Burlina AB, Burlina AP: Application of the WHOQOL-100 for the assessment of quality of life of adult patients with inherited metabolic diseases. Mol Genet Metab 2012, 106:25-30.

23. Eminoglu TF, Soysal SA, Tumer L, Okur I, Hasanoglu A: Quality of life in children treated with restrictive diet for inherited metabolic disease. Pediatr Int 2013, 55:428-433.

24. Muelly ER, Moore GJ, Bunce SC, Mack J, Bigler DC, Morton DH, Strauss KA: Biochemical correlates of neuropsychiatric illness in maple syrup urine disease. J Clin Invest 2013, 123:1809-1820.

25. Beauchamp MH, Boneh A, Anderson V: Cognitive, behavioural and adaptive profiles of children with glutaric aciduria type I detected through newborn screening. J Inherit Metab Dis 2009, 32(Suppl 1):S207-213.

26. Grünert SC, Mullerleile S, De Silva L, Barth M, Walter M, Walter K, Meissner T, Lindner M, Ensenauer R, Santer R, Bodamer OA, Baumgartner MR, Brunner-Krainz
M, Karall D, Haase C, Knerr I, Marquardt T, Hennermann JB, Steinfeld R, Beblo S, Koch HG, Konstantopoulou V, Scholl-Bürgi S, van Teeffelen-Heithoff A, Suormala T, Sperl W, Kraus JP, Superti-Furga A, Schwab KO, Sass JO: Propionic acidemia: clinical course and outcome in 55 pediatric and adolescent patients. Orphanet J Rare Dis 2013, 8:6

27. Krivitzky L, Babikian T, Lee HS, Thomas NH, Burk-Paull KL, Batshaw ML: Intellectual, adaptive, and behavioral functioning in children with urea cycle disorders. Pediatr Res 2009, 66:96-101.

28. Packman W, Henderson SL, Mehta I, Ronen R, Danner D, Chesterman B, Packman S: Psychosocial issues in families affected by maple syrup urine disease. J Genet Couns 2007, 16:799-809.

29. Pohorecka M, Biernacka M, Jakubowska-Winecka A, Biernacki M, Kusmierska K, Kowalik A, Sykut-Cegielska J: Behavioral and intellectual functioning in patients with tyrosinemia type I. Pediatr Endocrinol Diabetes Metab 2012, 18:96-100.

30. Sprangers MAG, Schwartz CE: Integrating response shift into healthrelated quality of life research: a theoretical model. Soc Sci Med 1999, 48:1507-1515

31. Upton P, Lawford J, Eiser C: Parent-child agreement across child healthrelated quality of life instruments: a review of the literature. Qual Life Res 2008, 17:895-913.

32. Eiser C, Varni JW: Health-related quality of life and symptom reporting: similarities and differences between children and their parents. Eur J Pediatr 2013, 172:1299-1304.

33. Hatzmann J, Valstar MJ, Bosch AM, Wijburg FA, Heymans HS, Grootenhuis MA: Predicting health-related quality of life of parents of children with inherited metabolic diseases. Acta Paediatr 2009, 98:1205-1210.

34. Landolt MA, Nuoffer JM, Steinmann B, Superti-Furga A: Quality of life and psychologic adjustment in children and adolescents with early treated phenylketonuria can be normal. J Pediatr 2002, 140:516-521.

35. Moher D, Liberati A, Tetzlaff J, Altman DG: Preferred reporting items for systematic reviews and meta-analyses: the PRISMA statement. PLoS Med 2009, 6:e1000097.

36. Dulfer K, Duppen N, Van Dijk AP, Kuipers IM, Van Domburg RT, Verhulst FC, Van der Ende J, Helbing WA, Utens EM: Parental mental health moderates the efficacy of exercise training on health-related quality of life in adolescents with congenital heart disease. Pediatr Cardiol 2014, doi:10.1007/s00246-014-0961-z.

37. Agostini A, Moretti M, Calabrese C, Rizzello F, Gionchetti P, Ercolani M, Campieri M: Attachment and quality of life in patients with inflammatory bowel disease. Int J Colorectal Dis 2014, 29(10):1291-1296.

\section{doi:10.1186/s13023-014-0159-8}

Cite this article as: Zeltner et al:: Quality of life, psychological adjustment, and adaptive functioning of patients with intoxication-type inborn errors of metabolism - a systematic review. Orphanet Journal of Rare Diseases 2014 9:159.

\section{Submit your next manuscript to BioMed Central and take full advantage of:}

- Convenient online submission

- Thorough peer review

- No space constraints or color figure charges

- Immediate publication on acceptance

- Inclusion in PubMed, CAS, Scopus and Google Scholar

- Research which is freely available for redistribution 